\begin{tabular}{|ccc|}
\hline & ANNALES INSTITUTI SLAVICI \\
& UnIVERSITATIS DEBRECENIENSIS & \\
SLAVICA XLVII & 2018 & DEBRECEN \\
\hline
\end{tabular}

\author{
Наталья МАТВЕEВА
}

\title{
ОСНОВЫ СМЫСЛОВОГО АНАЛИЗА СОЦИАЛЬНЫХ ЯВЛЕНИЙ В КОНЦЕПЦИИ С. Л. ФРАНКА
}

\author{
The Outlines of Meaning's Analysis of Social Phenomena \\ in the Concept of S. L. Frank
}

The present paper deals with the problem of how cultural meanings are perceived in S. L. Frank's social theory. His conception lies between two main paths of sociological thought: Durkheim's cognition of social facts as objective phenomena on the one hand, and Weber's cognition of subjective meanings of personal actions, on the other. In his theory Frank concentrates on the concept of objective forming idea-force, which resembles the concept of social fact in its quality of exerting pressure on individual consciousness and volition, but it should be brought into harmony with interpretive methodology. In Frank's view social ideas are regarded as a force forming social relations and therefore lie in the foundation of social institutions. These are, for example, ideas of state, of family, of friendship and so on. Social ideas are connected with the consciousness of the individual by their moral force. That is why such ideas are accepted by the individual at the emotional level of his spiritual life, because they believe that these ideas are true and organize their meanings and activities according to them. Thus social meanings of moral good or evil in human relations and in the social structure arise. At the same time they signify the emergence of sacred phenomena in society. Human beings, according the Frank's theory, have an internal need to be possessed by the sacred senses that give them the feeling of the participation in the implementation of the transcendent goals. Society is an objective living idea which provides sacred meanings for the individual. On the whole, a society's life is formed by the historically specific complex of ideas that are freely accepted or rejected by individuals and determine their feelings and behavior. There is no contradiction between personal freedom, creativity and social structure in S. Frank's theory. The author of the present paperfinds similarities between S.Frank's ideas and the fundamentals of cultural sociology.

Keywords: Semen Ludvigovich Frank, Russian religious philosophy, an objective forming idea-force, Jeffrey C. Alexander, a meaning of social phenomenon, a cultural sociology, a social idea, an interpretive methodology

В поисках подходов к социальному познанию, неразрывно связанных с традициями социологической науки, и, в то же время, раскрывающих перед ней новые горизонты, современные ученые все чаще обращаются к понимающей парадигме с ее центральными понятиями ценностей и смыслов общественной жизни. В то же время в русской социологии продолжаются поиски «своего лица», собственного характера социологического творчества, который не может возникнуть иначе, как на основе традиций мысли, переживших свое 
время. Исследователями отмечается недостаточная изученность методологических оснований социальных наук, предложенных русскими дореволюционными мыслителями, акцентировавшими внимание на смысловых и ценностных основах социальной жизни ${ }^{1}$. Одним из таких ученых является Семен Людвигович Франк (1877-1950), идеи которого вызывают значительный интерес у современных исследователей ${ }^{2}$. Сам философ был уверен в том, что традиции русской мысли, сформировавшиеся в дореволюционную эпоху, не будут забыты на его родине. Исследования в области социальной проблематики Франк проводил в течение всей его творческой жизни, начиная с увлечения марксизмом. Этот интерес был обусловлен взаимосвязанными причинами личного, исторического и философского характера [НАЗАРОВА 2007: 145-156]. Наибольшее внимание общественным вопросам ученый уделил в российский период своего творческого пути, а также в ранний период эмиграции (с 1922 по 1930 годы). Работы, в которых изложены его социально-философские и социологические идеи, это, в первую очередь, «Очерк методологии общественных наук» (1922) и «Духовные основы общества» (1930), а также ряд статей и рецензий.

Современными учеными признано, что философские и социальные идеи С.Л. Франка лежат в русле европейской и мировой социальной мысли ${ }^{3}$. Западные исследователи проявляют интерес к его социально-философскому творчеству ${ }^{4}$. Его концепция логически связана с ведущими направлениями классической социологии - понимающим подходом М. Вебера, социологизмом Э. Дюркгейма, формальной социологией Г. Зиммеля, феноменологией. При этом творчество ученого остается самобытной попыткой постановки и решения ряда теоретических проблем социологического дискурса, среди которых центральное место занимает проблема методологии. В данной статье мы сосредоточим внимание на понятии «объективная живая идея», являющемся центральным в социологической концепции Франка. В нем выражается действенное начало, формирующее общественное единство и направляющее общественное развитие.

\section{Предмет социального познания}

Постановка С.Л. Франком проблемы предмета и метода социальной науки по своему характеру совпадает с классической ее постановкой, заключающейся в вопросе о том, что именно из разнообразных проявлений общественной жизни людей должно ею изучаться. Русский ученый взялся за ее разработку в то время, когда уже вышел в свет «Метод социологии» Э. Дюркгейма (1895, русский перевод - 1899), были опубликованы основные работы М. Вебера методологического характера. Для оценки того вклада, который внес С.Л. Франк в развитие социологической теории, важно понимать общенаучные предпосылки возникновения его оригинального взгляда на исследование общества.

См.: МИКЕШИНА-ФРАНК: 142-160.

2 Вот некоторые из изданий, посвященных творчеству С.Л. Франка: Порус 2009а; Порус 2012; Антонов 2015.

3 См.: МотрошиловА 2006; Порус 2009а.

4 См., например: BoOBByER 2015; SwOBODA 1995: 259-290. 
Принципы познания общества в классической социологической мысли развивались в двух направлениях. Первое было основано Эмилем Дюркгеймом, выдвинувшим положение о том, что социальные явления выступают в качестве фактов, внешних и принудительных по отношению к индивидам. Их принудительный характер обусловлен тем давлением, которое оказывает сознание группы на сознание ее членов [ДюРКгЕйм 1991: 404]. В этой связи Э. Дюркгейм отмечал, что, хотя социальные явления основаны на идеях, составленных о них людьми [Там же, с. 424], однако их исследование должно проводиться не как исследование идей. Основой для объективно-научного исследования могут служить, по его мнению, только внешние по отношению к индивидам признаки и проявления социальной жизни. Так, общественная солидарность есть явление, само по себе, в своей внутренней основе, не поддающееся точному наблюдению или измерению. Именно поэтому внутренние духовные характеристики социальной солидарности необходимо заменить внешними фактами, которые могли бы ее символизировать. Такими фактами являются нормы права, а также нравы [Там же, с. 65-67].

Вопреки установке на изучение внешних, поддающихся наблюдению, фактов, в центре внимания автора «Метода социологии» всегда было общественное сознание, или коллективные представления. Нормы, ценности, аномию, феномен священного, - эти и другие социальные явления он рассматривал со стороны их внешних, объективных по отношению к индивиду, проявлений. Этот метод дал возможность совершения целого ряда научных открытий, таких как открытие социальных причин суицидального поведения, преступности, установление факторов общественной солидарности. Более позднее творчество классика, заглянувшего в смысловые глубины социального [DURKHEIM 2008], оказалось столь современным, что на его основе был создан мощный познавательный инструмент культурсоциологии [АЛЕКСАНДЕР 2013]. Однако метод, предполагавший отказ от рассмотрения социальных идей и смыслов в их внутреннем содержании, как особых явлений, был ограничен в своих познавательных возможностях, что и обусловило необходимость развития альтернативной методологии - понимающей.

Макс Вебер, на основе идей немецкого неокантианства, предложил другой путь исследования общества. Он не считал возможным отказываться от изучения смыслов социальных явлений в пользу их институциональных проявлений. Формулирование смыслов, по его убеждению, является исключительной принадлежностью индивидуальных сознаний. Поэтому социология призвана исследовать те смыслы, которые вкладывают индивиды в свои действия, и с помощью которых они интерпретируют действия других людей [ВЕБЕР 1990]. При этом, однако, в центре исследований Вебера был анализ крупных социально-культурных образований, таких как западный капитализм, протестантизм, буддизм. Поэтому ученый столкнулся с методологической проблемой, состоящей в необходимости объединить номиналистический подход к смысловой структуре общественной жизни с целями и задачами познания макросоциальных процессов. 
Метод понимания индивидуальных смыслов не вел напрямую к познанию явлений культуры, создающих общественное единство. Скорее, логика его развития ведет к возникновению социологии повседневности. Но Вебер, следуя запросам своего времени, стремился разработать концепцию, объясняющую макросоциальные процессы. Необходимо было разработать такой способ исследования общественных явлений, который позволил бы понять общее при помощи изучения уникальных смыслов индивидуального поведения.

Вебер нашел следующий выход из указанного положения. По его мнению, понять социальные смыслы возможно только с помощью выявления тех общих значений, которые придают индивиды своим и чужим социальным действиям. Для этого их необходимо рационально реконструировать, создав особые научные построения - «чистые типы» смыслов, свободные от вариаций, обусловленных индивидуальными особенностями [ВЕБЕР 1990: 603]. Таким образом, речь у Дюркгейма и у Вебера шла об исследовании одной и той же смысловой реальности коллективного сознания, но в рамках разных подходов. Точкой расхождения методологических принципов был вопрос о том, является ли эта реальность результатом работы индивидуальных сознаний или особым коллективным феноменом, принудительным для индивидов.

Для надлежащей оценки вклада С.Л. Франка в современную социологию необходимо понимать основные черты дальнейшего развития указанных направлений (получивших наименование структурной и интерпретативной парадигм). Оно шло разными путями - от углубления анализа некоторых исходных смысловых принципов культуры (в структурализме), изучения смысловых аспектов взаимодействия (в феноменологии, герменевтике, этнометодологии, символическом интеракционизме и других теориях) до попыток объединить или примирить обе парадигмы. Многие ведущие социологи XX в., такие, как Э. Гидденс и П. Бурдье, пошли по пути реконструирования процесса взаимного влияния внешних по отношению к индивиду социальных структур и духовно-смысловых усилий индивидуальных сознаний. С этого же начал создание структурного функционализма Т. Парсонс, отбросив при этом фундаментальную идею П. Сорокина об идеально-смысловой основе суперсистем культуры. В его концепции общество было представлено в форме нормативно-упорядоченной системы, основанной на социально-осмысленных (по Веберу) действиях индивидов, существование которой сводилось к выполнению функций, отвечающих потребностям людей. Индивидуальные осмысленные действия при этом превратились в исполнение социальных ролей. Так было проинтерпретировано взаимодействие индивидуальных смыслов со смыслами общими, воплощенными в социальных структурах, принудительными для индивидуальных сознаний. Однако центральная проблема социологического познания была перенесена из плоскости исследования социальных явлений как фактов особого рода (на чем настаивал Дюркгейм) в плоскость изучения процесса взаимодействия общественных структур с индивидуальным сознанием. Задача исследования смыслов социальных явлений как особых образований, не имеющих вторичного характера ни по отношению к индивидуальным смыслам, ни 
по отношению к функционированию внешних социальных институтов, осталась, таким образом, вне поля зрения исследователей.

Социологи отмечают произошедший в последней трети $\mathrm{XX}$ в. «культурный поворот» в изучении общества, который, казалось бы, мог восполнить этот пробел, поскольку традиционно именно культура трактуется как сфера смыслов и ценносте ${ }^{5}$.Среди исследователей смыслов культуры можно выделить Дж. Александера и ученых его школы, на творчество которых оказали влияние работы М. Вебера, Э. Дюркгейма, В. Дильтея и Ф. де Соссюра [КуРАКин 2013: 31]. Это направление заявило о необходимости «культурной автономии» или методологического отделения сферы культуры от социальной структуры в целях понимания роли смыслов социальной жизни в процессе общественного развития [АЛЕКСАНДЕР 2013: 57-61]. Это направление можно считать определенным прорывом в социологии, «сильной программой», которая объявила о радикальном методологическом повороте от рассмотрения смыслов как переменных, зависимых от внешних социальных институтов и интересов, к рассмотрению их в качестве причин формирования «объективных структур» и событий «реального социального мира» [Там же, с. 92-93].

По мнению Дж. Александера, на протяжении большей части истории своего развития социология характеризовалась определенной нечувствительностью к проблемам смысла [Там же, с. 65]. Однако русская социологическая традиция, сформировавшаяся до революции 1917 г. по преимуществу в рамках религиозной философии и русской ветви неокантианства и продолжившая свое развитие в условиях эмиграции, остается практически неисследованной и неизвестной в мировой социологии. Тем не менее, она сохраняет свой эвристический потенциал и сегодня. Перспективы в этом отношении открываются в направлении логико-смысловых исследований социальных явлений. Концепция С. Л. Франка, являющаяся органической частью этой традиции, содержит ряд открытий и выводов, понимание которых дает возможность исследования социальных смыслов как объективных явлений, имеющих ценностные основы, или культурную почву, находящихся в живых, активных взаимоотношениях с другими смыслами и с социальной реальностью в целом.

\section{Сущность социальных явлений по Семену Франку}

Позиция С.Л. Франка состоит в утверждении методологического приоритета исследования смысловых компонентов общественной жизни над изучением ее эмпирических проявлений, составляющих, по его мнению, поверхностную, внешнюю часть этой жизни. Эта позиция восходит к платоническим тенденциям в русской философской мысли, основанным на представлении о том, что истинное соотношение явлений раскрывается в принципе их происхождения от единства Абсолюта и проявлении в разнообразии реального мира. Логическое познание конкретизирует интуитивное познание Абсолюта в ме-

5 См.: BonNell 1999; FriedLAND 2004. 
тафизических и этических понятиях, т.е. в тех идеях, которые сближают познание Абсолюта с познанием реального мира [DOBIESZEWSKI 2010]. Общество, по мнению Франка, есть реальность, онтологически единая с Абсолютом: «в основе общества лежит некое мистическое, сверхприродное всеединство. Ядро и как бы животворный зародыш общества, его внутренняя живая энтелехия, есть соборное единство внутренней духовной жизни, жизни в Боге» [ФРАНК 1991: 355]. Это обусловливает ярко выраженные мистические свойства общества, проявляющиеся как в изначальном свойстве соборности, так и в наличии онтологических законов социальной жизни, которые можно нарушать только ценой упадка и болезни общества.

В основе концепции Франка лежит утверждение о том, что общественные явления, в своей основе, духовны, а не материальны [Там же, с. 317]. Это означает, что они не заключаются в эмпирических фактах, которые неизбежно сопутствуют, скажем, войне, революции, собранию людей, подписанию договоров и т.п. Реальные события являются как бы спутниками социальных явлений, подлинное существо которых составляет смысл, не имеющий непосредственного отношения к физическим (материальным) процессам. Общественная жизнь, по мнению ученого, связана с физической действительностью, в первую очередь постольку, поскольку она выражается в человеческих действиях - эмпирических выражениях жизни личности. Тем не менее, связь социального с материальным в общественной жизни - это связь двух разрядов явлений, а не выражение внутренней сущности социального.

Мыслитель акцентирует внимание на том, что общество в тех его признаках, которые образуют его специфический характер, вообще не может изучаться как чувственное явление, материальный факт [Там же, с. 317]. Его познание лежит на путях внутреннего духовного освоения смысловых, идеальных оснований социальных явлений. Именно на этой основе Франк отрицает возможность познания общества с помощью позитивных методов, включая биологические или физические попытки его истолкования. Ученый поясняет, что, например, вывешенные на улицах Виттенберга тезисы Лютера внешне ничем не отличались от других афиш и плакатов, а их отличие, повлиявшее на европейскую и мировую историю, коренилось в тех идеях и смыслах, которые заключались в этих тезисах. Если бы некто, скажем, с другой планеты, ничего не знающий о человеческом обществе, стал исследовать только происходящие в нем эмпирические события, не пытаясь вникнуть в их смысл и духовное содержание, то для такого исследователя случайные скопления людей на улицах или в очередях значили бы больше, чем величайшие реформы, разработанные в тиши кабинетов, а уличные плакаты - больше, чем музейные экспонаты или полотна великих мастеров. По мнению Франка, какое бы явление социальной жизни мы не взяли - будь то семья, государство, нация, революция и т.д. - мы не будем ничего знать о нем, если не применим методы сопереживания, соучастия в понимании этого явления. Данное положение, безусловно, дает основание отнести его концепцию к понимающей парадигме в социологии. 
Однако Франк убежден, что социальные явления характеризуются собственными внутренними смыслами, отличными от смыслов индивидуальных. Эти смыслы объективны, т.е. независимы от сознания отдельных людей. Для их обозначения ученый предлагает использовать особый термин - «объективная живая идея-сила» [ФРАНК 1922: 77]. Данный термин принадлежит А. Фулье [ФРАнК 1991: 368]. Мыслитель поясняет, что эта идея объективна потому, что находится вне индивидуальных сознаний, имеет смысл, независимый от осознания ее тем или иным человеком; живая она потому, что выступает в качестве силы, определяющей действия, мнения и позиции людей. Она принудительно воздействует на их волю, заставляя воплощать себя на практике. Таким образом, объективная живая идея социального явления сочетает в себе признаки идеальности и реальности: будучи идеей, смыслом данного явления, она, в то же время, выступает как реальная сила.

При рассмотрении общественной жизни Франк дистанцируется от социального психологизма, причем его позиция в данном вопросе отличается продуманностью и глубиной. Он указывает, что психологизм в обществознании опирается на очевидный факт связанности социальной жизни, как комплекса человеческих действий, с внутренней жизнью личности, и даже укорененности в ней. Жизнь общества, как может казаться, складывается из человеческих устремлений, чувств и представлений. Однако нельзя не заметить и существенного, коренного отличия явлений общественной жизни от психических явлений, даже взятых в их межличностном, социально-психологическом, аспекте. Прежде всего, психические явления всегда существуют внутри человека, в его субъективном восприятии или сознании, в то время как социальные явления обнаруживаются вне субъекта. По мнению ученого, социальные явления образуют внешнюю среду жизнедеятельности личности, причем реальность общества своей объективностью напоминает реальность материальных вещей: «государство, закон, власть, быт и пр. суть что-то устойчивое, непроницаемое, жесткое, и если я добровольно не хочу считаться с этой объективной реальностью, я обречен расшибить себе лоб об нее, как при столкновении с камнем или стеной» [ФРАНК 1991: 319].

Ученый возражает и против позиции, состоящей в том, что социальные явления представляют собой результат психологического взаимодействия людей. По его мнению, дело в том, что эта позиция не способна объяснить наличие социальной среды, в которой существуют люди, и в которой происходит их взаимодействие. Социально-психологические явления, то есть явления, совершающиеся в душах людей под воздействием других людей, не могут быть отнесены к социальным явлениям, считает Франк, поскольку они не обладают основным признаком социального явления - существованием вне индивида. Если взаимодействие имеет своим результатом какие-либо изменения, произошедшие в переживаниях, взглядах, потребностях взаимодействующих людей, то оно, тем не менее, не есть внешний, объективный по отношению к этим индивидам, факт. Отсюда следует важный вывод о том, что социальные явления 
не могут рассматриваться в качестве результата психологического взаимодействия людей и не могут быть объяснены, исходя из рассмотрения таких взаимодействий. Он настаивает на сверхличном характере социальных явлений, что, таким образом, выводит их за пределы всего психологического.

Как видим, трактовка социальных явлений Франком полностью совпадает с трактовкой социальных фактов Дюркгеймом, как объективных по отношению к индивидуальному сознанию, напоминающих материальные вещи характером своего воздействия на индивида. Однако, по сравнению с подходом классика французской социологии, Франк выдвигает на первый план исследование идеально-смысловых свойств социальных явлений. Методология социального познания состоит в понимании объективных смыслов, или идейсоциальных явлений, но при этом не совпадает с веберовской методологией понимания субъективных смыслов, вкладываемых в них людьми. По мнению Франка, следует изучать объективные смыслы социальных явлений, не зависящие от индивидуальных сознаний, при этом формирующиеся в процессе социальной жизни.

\section{Социальное явление как объективная живая идея}

По меткому замечанию О.А. Назаровой, «принадлежность к "секте платоников" требовала от него обращения к духовным основам того или иного исторического феномена» [НАЗАРОВА 2007: 154]. Франк обращает внимание на тот факт, что при всем своем абстрактно-определяемом сходстве с вещами материального мира, социальные явления имеют столь же четкие отличия от них. Социальные явления принадлежат, судя по их коренному отличию как от материальных явлений, так и от явлений психических, к некоторому третьему роду бытия, полагает ученый. Но такой вид явлений можно назвать идеей в смысле объективного идеального содержания бытия, выраженного в термине «эйдос» Платона. Иными словами, социальное бытие предстает как бытие, образуемое объективными идеями. Объективное идеальное содержание бытия, по Франку, является, с одной стороны, оформляющим элементом действительности, с другой - входит в состав духовного мира, характеризуясь, таким образом, монодуализмом, или двойственным единством [АКУлич 2011: 108-113].

Для лучшего понимания самой возможности таких идей Франк обращается к аналогичным идеям, существующим в логике, математике и этике. Так, содержание суждения « 2 х $2=4$ » едино для всех, оно не зависит от осознания его людьми и имеет вневременный характер. Это суждение относится к миру объективных идей, по образцу которых мы должны мыслить и социальные явления. Однако очевидно, что социальные явления, например, революцию или заключение мира, невозможно представить в качестве подобных общеобязательных идей. Правда, замечает Франк, в социальной мысли существует направление, к которому принадлежат некоторые сторонники неокантианства, усматривающее сущность социального в праве, а право, в свою очередь, уже предстает как объективная идея, подобная вышеуказанным. Однако этот аргумент 
Основы смыслового анализа сочиильных явлений...

не достаточен. По его мнению, общественная жизнь отличается от сферы объективных идей математики, логики, этики и права именно тем, что их истины носят абстрактный характер, в то время как общественная жизнь всегда конкретна. Каждое социальное событие, закон или институт имеют свое течение во времени, они могут возникнуть или исчезнуть. Мало того, социальные явления не существуют вне отношения к ним людей, они возникают только в человеческом общении, а не в иных духовных сферах. Поэтому социальные явления невозможно представить в качестве абстрактных истин, существующих вне зависимости от деятельности людей, вне времени и пространства.

Итак, согласно Франку, социальные явления имеют идеальный характер, совмещенный с конкретностью проявления и воплощения в объективном мире. Они представляют собой объективные идеи, которые не могут быть оторваны от конкретной действительности человеческой жизни, - так предстает сущность социального в трактовке Франка. Общественная жизнь есть процесс воплощения живых, борющихся идей, а не некое статичное бытие, и этот процесс воплощения полон исканий и заблуждений, открытий и свершений человеческого духа. Социальная жизнь есть, вместе с тем, реальная человеческая жизнь. Поэтому социальные идеи нельзя рассматривать как абстракции, порожденные чьим-либо умом, - надо искать их связь с конкретной социальной действительностью.

Каким же образом могут существовать объективные идеи, неразрывно слитые с конкретной действительностью? Мыслитель дает следующий ответ на этот вопрос. Социальное явление в своем объективно-идеальном бытии предстает как идея-образец, цель для человеческой деятельности, сила, воздействующая на волю людей в направлении ее реализации в качестве идеала. В этой связи ученый еще раз указывает на разницу между общественным явлением и явлением любого взаимодействия между людьми. Люди могут взаимодействовать между собой, но если в этом общении нет начала, обнаруживающего себя как должное, обязательное для участников взаимодействия, то такое общение нельзя назвать социальным явлением. Социальное явление имеет место только там, где есть начало, подчиняющее себе поступки людей и направляющее их волю в определенном направлении. Например, дружба как социальное явление возникает, когда люди осознают себя друзьями и подчиняются требованиям, налагаемым представлениями о данном союзе. В случае простой симпатии и даже частых встреч между людьми может не быть никакого социального отношения, - такие отношения, согласно мысли Франка, будут просто социально-психологическим взаимодействием. Точно так же власть как социальное явление имеет место только в том случае, если и властвующие, и подчиненные осознают свои отношения в рамках общей идеи власти, согласны с ней. Если же господство осуществляется лишь с помощью принуждения и силы, но не является признанным подчиненной стороной, то в этом случае власть как социальное явление, по мнению ученого, отсутствует [ФРАнК 1991: 325-326]. Иными словами, социальное явление как объективная идея, воздействующая на волю людей, для своего существования должна быть 
признана индивидами, принята ими как часть собственных убеждений или мотивов, установок деятельности. В противном же случае, конкретное социальное явление перестает существовать. Отсюда можно сделать методологический вывод о том, что при рассмотрении идеи соииального явления следует выявить те общественные группы, которые эту идею разделяют.

Франк акцентирует внимание на, казалось бы, несовместимых, противоположных свойствах социальной жизни: субъективности (т.е. признанности социального отношения людьми) и объективности (существовании вне сознания индивидов). Для объяснения этих противоположных качеств нет необходимости прибегать к каким-то дополнительным допущениям или объяснениям: достаточно просто признать их как факт, признать их действительность, полагает ученый. Такое соединение противоположных свойств, по его мнению, свидетельствует о духовном характере социальной жизни, так как именно духовная жизнь демонстрирует возможность быть одновременно субъективной, исходящей из глубины души, и объективной, воплощающейся в материальной форме, скажем, в произведениях искусства. Социальная жизнь, по мнению Франка, входит в состав духовной жизни как ее часть, направленная на внешнее обнаружение и воплощение. Объективная социальная идея является результатом работы человеческого духа, но при этом она властвует над ним через акт его веры и служения. Так, ученый полагал, что русская революция как социальное явление была обусловлена взаимодействием двух объективных тенденций в развитии социальных смыслов - рационализации западноевропейского общества и религиозного максимализма русского народа [НАЗАРОВА 2009: 125].

Эмоционально-принудительный характер социальных идей обусловливает их мистические свойства, под которыми ученый подразумевал выход за пределы человеческого бытия, направленность к целям, превосходящим эмпирические человеческие нужды и потребности. По его словам, «то, что общество есть всегда нечто большее, чем комплекс фактических человеческих сил, именно система объективных идеально формирующих сверхчеловеческих идей, есть лучшее свидетельство, что человеческая жизнь есть по самому своему существу жизнь богочеловеческая» [ФРАНК 1991: 330].

Здесь следует подчеркнуть, что теория мыслителя об объективных социально-формирующих идеях подразумевает наличие священного как особого свойства общественной жизни. Он обозначает это свойство словом «мистичное», что не меняет смысловой нагрузки данного термина. Социальная жизнь, по его мнению, образуется целой системой божественных (т.е. священных!) сил, в которых проявляется исторически-конкретное понимание людьми смыслов и ценностей, иными словами, определенное отношение человека к абсолютной правде.Человек выступает проводником высших начал, которым он служит, подчиняет свои усилия, но не просто проводником, а личностью, творчески участвующей в их осуществлении. Современные исследователи отмечают, что социальная идея, объективная по отношению к индивиду, в концепции Франка реализуется только через внутреннее принятие ее личностью и де- 
ятельность по ее воплощению [МАКАРОВА 2010]. Личность творчески преобразует всеобщие культурные универсалии в индивидуально-конкретные смыслы [Порус 2009б: 18].

\section{Социальная идея как моральная сила}

В творчестве Франка особую роль играет этический компонент его социальных идей [ДЕМЕНТЬЕВА 2005]. Человек, полагал ученый, есть существо нравственное, но не в смысле объективной чистоты его мыслей и поступков, а в смысле того, что он всегда ищет идеально-нравственное оправдание своей деятельности [ФРАНК 1991: 367]. Социальные идеи жизненны именно потому, что они, будучи укоренены в человеческом сердце, воспринимаются как долг, требующий своего осуществления на практике. Они выступают, таким образом, с одной стороны, как основа социальной жизни и всех ее институтов (социальных явлений), с другой стороны - как мощнейший фактор любых социальных изменений.

Этот нравственный характер социальных идей обусловлен самой природой общества, как сферы, в которой реальные, природно-материальные силы человеческого бытия соединены со сверхчеловеческим началом должного, проистекающего из глубин человеческого духа. Как отмечает Филипп Свобода, современный американский исследователь творчества С. Франка, эти идеи, генетически связанные с идеями неокантианства, ставят сложную проблему взаимодействия личности и общества. Личность находит в глубине своего духа потребность реализации абсолютных и объективных ценностей - добра, красоты, истины, гармонии, причем чувствительность и отзывчивость личности к этим ценностям свидетельствуют об уровне ее достоинства. Однако трагедия человеческой жизни заключается в том, что мир конкретной действительности, в котором человек проявляет свою активность, не отражает в себе этот космический порядок ценностей и сопротивляется своему изменению в соответствии с ним [SWOBODA 1995: 262].

В этой связи можно сопоставить идеи Франка с тезисом культурсоциологии о том, что социальные смыслы, направленные на священные (имеющие особую, исключительную значимость для общества) объекты, имеют бинарную структуру, делящую мир на два противоположных полюса - абсолютного добра и абсолютного зла [АЛЕКСАНДЕР 2013: 311-312]. Такая структура социальных смыслов и есть структура нравственного порядка, определяющая должное и запретное в человеческих действиях.

Согласно концепции Франка, идея социального явления есть оформляющее начало социальной жизни, то есть начало институциональное. В основе социального порядка, по его мнению, лежат не стихийно-природные страсти и инстинкты, а именно формирующая нравственная идея. Например, семья как социальное установление формируется не благодаря половой страсти, а, напротив, благодаря живым идеям любви, верности, нравственной связи между супругами и долга по отношению к детям. Экономический строй обще- 
ства создается не по причине наличия голода и иных материальных потребностей людей, а вследствие идеального осознания людьми необходимости общей связи их трудовых усилий, их регламентации, признанием за другими наличия трудовых и экономических прав, как участников общей экономической системы. Эти и другие примеры убедительно доказывают обоснованность теоретических положений Франка.

Необходимо учитывать, что именно идеально-нравственное начало ученый считает глубинной основой общественного бытия, в противоположность концепциям, кладущим в его основу материальные потребности людей или скрытые инстинкты (к каковым он относит марксизм и фрейдизм). Идеальное начало социальной жизни соединяется, однако, с эмпирически реальным таким образом, что на ее поверхности чаще обнаруживаются проявления материальных потребностей и психологических страстей, идеальный же момент оказывается скрыт под этими внешними наслоениями. Но от этого мощь его воздействия на общество и на поведение индивидов не становится слабее. Вдумчивый наблюдатель социальных процессов сможет обнаружить за внешними проявлениями социальной жизни идеальные стремления и верования живого нравственного сознания людей, всегда оказывающимся сильнее расчетов мнимо-реальной «трезвой» политики корысти и интересов, презирающей нравственные идеи [ФРАНК 1991: 368].

Согласно указаниям Франка, вышесказанное не означает, что социологическое познание должно исключить изучение, скажем, данных статистики или наблюдений над материальной составляющей социальных структур и процессов. Однако такое знание, в случае использования его как основного или единственного инструмента анализа, будет лишь скользить по поверхности общественных явлений, не проникая в их внутреннюю суть. Изучение общества может также использовать сравнительные, исторические и генетические методы, дающие лучшее понимание хода социальных процессов и возможности для их научной оценки, но и в этом случае результат исследования не будет достаточно полон. Лишь третий уровень социального познания - уровень глубинного понимания и анализа смыслов социальных событий и явлений - может отвечать требованиям истинного социального знания [ФРАнК 1992: 326-327].

\section{Заключение}

Таким образом, основным методологическим принципом анализа общества в концепции Франка выступает понимание глубинных духовных смыслов происходящих событий. Это понимание строится на выявлении лежащих в их основе объективных идей, которые характеризуются нравственным характером, определяющим должное в деятельности людей.

Концепция Франка дает определенный ответ на вопрос о взаимосвязи духовного мира личности и объективных структур социальной жизни. В ней снимается противоположность между внутренней свободой и самодеятельностью личности и принудительным характером социальных институтов. Это снятие 
указанной противоположности обусловлено утверждением о том, что основным свойством социального явления выступает формирующая объективная идея, эмоционально принимаемая индивидом в качестве должного. Воздействие идеи на человеческую волю происходит не как внешнее принуждение, а как внутреннее принятие на самом глубоком уровне личности, сопровождающееся потребностью в ее реализации. Социальная жизнь выступает в качестве исторически-конкретного комплекса таких идей, свободно принимаемых индивидами или отвергаемых ими.

\section{Литература}

Акулич 2011: Акулич, Н.М. Методологические основания философии культуры С.Л. Франка // Вестник Балтийского федерального университета им. И. Канта. 2011/12: 108-113.

АЛЕКСАНДЕР 2013: Александер, Дж. Смыслы социальной жизни: культурсоциология. Москва: Праксис.

Антонов 2015: Самый выдающийся русский философ: философия религии и политики С.Л. Франка. Сборник научных статей / сост. К.М. Антонов. Москва: Издательство ПСТГУ.

ВеБЕР 1990: Вебер, М. Основные социологические понятия // Вебер М. Избранные произведения. Москва: Прогресс.

ДЕмеНтьЕВА 2005: Дементьева, Л.С. Социально-политические идеи С.Л. Франка в контексте его метафизической системы. Автореферат дисс. канд. филос. наук. Хабаровск.

ДюркГЕйм 1991: Дюркгейм, Э. О разделении общественного труда. Метод социологии. Перевод с французского А.Б. Гофмана. Москва: Наука.

КурАКин 2013: Куракин, Д.Ю. Социологическая грамматика культурных смыслов (предисловие) // Александер Дж.Смыслы социальной жизни: культурсоциология. Москва: Праксис.

МАКАРОВА 2010: Макарова, Л.В. Концепция личности в русской религиозной мысли: историко-социологический анализ. Дисс. канд. социол. наук. Москва: РГСУ.

МиКЕшиНА-ФРАНК 2009: Микешина, Л.А., С.Л. Франк: проблемы методологии обществознания. Из истории социальной эпистемологии // Эпистемология и философские науки. Т. XXII. № 4: 142-160.

МотрошилОвА 2006: Мотрошилова, Н.В. Мыслители России и философия Запада (В. Соловьев, Н. Бердяев, С. Франк, Л. Шестов). Москва.

НАЗАРОВА 2007: Назарова, О.А. Швейцарские публикации Семена Людвиговича Франка // Вопросы философии. 2007, № 1: 145-156.

НАзАРОВА 2009: Назарова, О. Философия истории Семена Людвиговича Франка // Вопросы философии, 2009, № 1: 125-136.

ПоруС 2009а: Порус, В.Н. (ред.) Идейное наследие С.Л. Франка в контексте современной культуры. Москва: Издательство Библейско-богословского института св. апостола Андрея.

Порус 2009б: Порус, В.Н. Онтология культуры С.Л. Франка // Философские науки. № 6: 8-28.

Порус 2012: Порус, В.Н. (ред.) Семен Людвигович Франк. Москва: РОССПЭН.

ФРАнК 1922а: Франк, С.Л. Очерк методологии общественных наук. Москва: Берег. 
ФРАНК 1922б: Франк, С.Л. Религиозно-исторический смысл русской революции // Русская идея (сост. М.А. Маслин). Москва: Республика.

ФРАнК 1991: Франк, С.Л. Духовные основы общества //Русское зарубежье. Лениздат.

BonNell 1999: Bonnell, V.E., HuntL. eds. Beyond the Cultural Turn: New Directions in the Study of Society and Culture. Berkeley: Univ. Calif. Press.

BOOBBYER 2015: Boobbyer, P. A Russian Version of Christian Realism: Spiritual Wisdom and Politics in the Thought of S. L. Frank (1877-1950) // International History Review. 1 January 2015, $21 \mathrm{p}$.

DoBIESZEWSKI 2010: Dobieszewski, J. Neoplatonic Tendencies in Russian Philosophy // Studies in East European Thought. Vol. 62, 1, Polish Studies in Russian Religious Philosophy (March 2010) 3-10.

DURKHEIM 2008: Durkheim, E. The Elementary Forms of Religious Life. New York: Oxford University Press.

FRIEDLAND 2004: Friedland, R., Mohr, J. Matters of Culture: Cultural Sociology in Practice. New York: Cambridge Univ. Press.

SwOBODA 1995: Swoboda, F. Windelband's Influence on S.L. Frank // Studies in East European Thought, Vol. 47, No. 3/4, Neo-Kantianism in Russian Thought (Dec., 1995).

Наталья МАТВЕEВА

Humanitarian Institution of the Russian Transport University (MIIT)

Moscow, Russia

pmatveyev@yandex.ru 